\title{
Sickle Beta Thalassemia
}

National Cancer Institute

\section{Source}

National Cancer Institute. Sickle Beta Thalassemia. NCI Thesaurus. Code C95539.

A heterozygous state in which a person has a hemoglobin $\mathrm{S}$ allele along with a beta-

thalassemia allele. The severity of the condition is determined to a large extent by the quantity of normal hemoglobin produced by the beta-thalassemia gene. 